\title{
Biomarkers associated with vascular and valvular calcification in chronic hemodialysis patients
}

\author{
Chien-Te Lee, ${ }^{\mathrm{a}, *}$, Sarah Chua ${ }^{\mathrm{b}}$, Chung-Yao Hsu ${ }^{\mathrm{c}}$, Yu-Che Tsai ${ }^{\mathrm{a}}$, Hwee-Yeong Ng ${ }^{\mathrm{a}}$, Chien-Chun Kuo ${ }^{\mathrm{a}}$, \\ Chien-Hsing $\mathrm{Wu}^{\mathrm{a}}$, Te-Chun Chen ${ }^{\mathrm{a}}$, Terry Ting-Yu Chiu ${ }^{\mathrm{a}}$ and Yueh-Ting Lee ${ }^{\mathrm{a}}$ \\ ${ }^{a}$ Division of Nephrology, Department of Internal Medicine, Kaohsiung Chang Gung Memorial Hospital and \\ Chang Gung University College of Medicine, Kaohsiung, Taiwan \\ ${ }^{\mathrm{b}}$ Division of Cardiology, Department of Internal Medicine, Kaohsiung Chang Gung Memorial Hospital and Chang \\ Gung University College of Medicine, Kaohsiung, Taiwan \\ ${ }^{\mathrm{c}}$ Dpartment of Neurology, Kaohsiung Medical University, Kaohsiung, Taiwan
}

\begin{abstract}
.
BACKGROUND: Cardiovascular calcification, including arterial intimal and medial calcification (AIC and AMC) and valvular calcification (VC) are important predictors of outcome in chronic dialysis patients. We aimed to compare their prevalence and analyze respective risk factors in hemodialysis (HD) patients.

METHODS: A total of $81 \mathrm{HD}$ patients were enrolled. Vascular calcification was assessed by plain film radiography of the pelvis and VC was diagnosed by echocardiography. Demographic data was reviewed and serum levels of calcification-relevant biomarkers were determined. Patients with and without calcification were then compared.

RESULTS: The prevalence study indicated that 36 patients had AIC (44.4\%), 17 had AMC (21\%) and 60 (74.1\%) had VC. Patients with vascular calcification were older, and had a higher prevalence of diabetes. Their IL-6, osteoprotegerin, and uric acid levels were higher. Serum fetuin-A was lower in patients with VC. Logistic regression analysis revealed age, uric acid and diabetes to be independently associated with AIC; uric acid, diabetes and osteoprotegerin with AMC. Fetuin-A was the sole associate of VC.

CONCLUSIONS: It is concluded that the prevalence of cardiovascular calcification in chronic HD patients was high with cardiac valve involvement more frequent. Factors associated with different type of calcification were not identical. Changes in biomarkers may represent clinical clues for assessment of cardiovascular calcification in HD patients.
\end{abstract}

Keywords: Vascular calcification, valvular calcification, hemodialysis, biomarker

\section{Introduction}

Cardiovascular disease is the leading cause of death in chronic dialysis patients. The underlying diseases such as diabetes, hypertension, advanced age, and

\footnotetext{
*Corresponding author: Chien-Te Lee, Division of Nephrology, Department of Internal Medicine, Kaohsiung Chang-Gung Memorial Hospital, 123, Ta-Pei Road, Niao-Sung District, Kaohsiung 833, Taiwan. Tel.: +886 77317123 EXT 8306; Fax: +886 7 7322402; E-mail: chientel@gmail.com.
}

chronic inflammation are all strongly related to survival in the dialysis population [1]. More recently, both the presence as well as the extent of cardiovascular calcification has been demonstrated to be predictors of cardiovascular and all-cause mortality in dialysis patients [2,3]. In one autopsy study, soft tissue calcification including the heart and kidney was identified in $79 \%$ of dialysis patients and $44 \%$ of nondialysis patients [4]. Coronary artery calcification has also been shown to be more prevalent after the onset of dialysis, being present in $65 \%$ of those patients [5]. 
In general, cardiovascular calcification are divided into three types, depending on the locations involved [6]: arterial intimal calcification (AIC), which is characteristic of atherosclerosis and causes plaque formation and significant luminal stenosis; arterial medial calcification (AMC), which is the nonendochrondral ossification process of the arterial tunica media and is highly characteristic of diabetes mellitus and chronic renal failure [7] and valvular calcification (VC), which occurs in response to mechanical stressors and inflammation, and thus recruit dystrophic mineralization and nonenchondral ossification processes to deposit calcium [8]. Clinical observational study has demonstrated that VC represents a marker of atherosclerosis and arterial calcification in dialysis patients [9]. Additionally, hemodialysis patients with AIC were reported to have higher mortality than those with AMC [10].

Mechanisms of cardiovascular calcification in dialysis patients are multiple $[11,12]$. A variety of biomarkers circulate in blood stream can be determined as a method of early detection of calcification. However, the role of these biomarkers in different type calcification has rarely been compared. In this study, we aim to investigate the distribution of vascular calcification and VC in hemodialysis patients. Novel relevant biomarkers of calcification were determined, and factors associated with calcification and their relationships were analyzed.

\section{Materials and methods}

\subsection{Patients}

A total of 81 stable chronic hemodialysis patients were randomly selected. All patients received regular hemodialysis with a biocompatible artificial kidney for a duration of 4 hours per session, 3 times a week, for at least 6 months, at our hospital. Exclusion criteria included young patients $(<18$ years old), viral hepatitis B or C carriers, recent infection (in the past 1 month), and patients using steroids or immunosuppressive agents. Patients with abnormal liver function tests or leukocytosis were also excluded from this study. The underlying causes of renal failure were chronic glomerulonephritis $(n=21)$, diabetes $(n=$ 19), hypertension ( $n=14$ ), and unknown etiology $(n=27)$. Demographic data including age, gender, and duration of dialysis therapy were collected. Comorbidity such as diabetes and hypertension was reviewed and recorded. Patients with previous history of acute myocardial infarction, stroke, peripheral artery disease were also reviewed. This study was approved by the Institutional Review Board of Chang Gung Memorial Hospital (97-0598B). Informed consent was obtained from all patients.

\subsection{Laboratory measurement}

Fasting blood samples were collected prior to hemodialysis upon the mid-week dialysis day. Their previous 12 months data of serum calcium, phosphate, parathyroid hormone, and albumin were collected and averaged. Blood levels of fetuin-A, osteoprotegerin (OPG), fibroblast growth factor 23 (FGF23), osteopontin (OPN), and inflammatory markers - highsensitivity C-reactive protein (hs-CRP) and interleukin -6 (IL-6) - were determined by commercial kits. All samples were stored at $-80^{\circ} \mathrm{C}$ until the analysis. HsCRP was measured using nephelometry (Behring Diagnostics, Marbury, Germany). IL-6 was measured by a quantitative sandwich enzyme immunoassay (R\&D Systems, Minneapolis, MN, USA). Serum fetuin-A was determined by a human fetuin-A enzyme-linked immunosorbent assay (ELISA) kit (Assaypro, St. Charles, MO, USA). Levels of OPG, OPN, and FGF23 were also detected using ELISA kits (Immundiagnostik, Bensheim, Germany; R\&D Systems, Minneapolis, MN, USA; and Immutopics, San Clemente, CA, USA, respectively). The adequacy of dialysis was assessed by $\mathrm{KT} / \mathrm{V}_{\text {urea }}$ and the urea reduction ratio (URR). The KT/ $\mathrm{V}_{\text {urea }}$ was determined using the urea kinetic model of Gotch [13].

\subsection{Definition and assessment of vascular and valvular calcification}

All subjects underwent radiography of the pelvis to determine the type of vascular calcification. According to London et al., cases showing the presence of discrete intimal-like plaques with irregular and patchy distribution were classified as AIC, and those with uniform linear railroad track-type calcification, as AMC. Patients with a mixed type of vascular calcification were classified as AIC [10]. Echocardiograms were performed and interpreted by a single experienced cardiologist who was also blinded to the subjects' clinical information. VC was defined as bright echoes of more than $1 \mathrm{~mm}$ on 1 or more cusps of the aortic and the mitral valves [3]. 


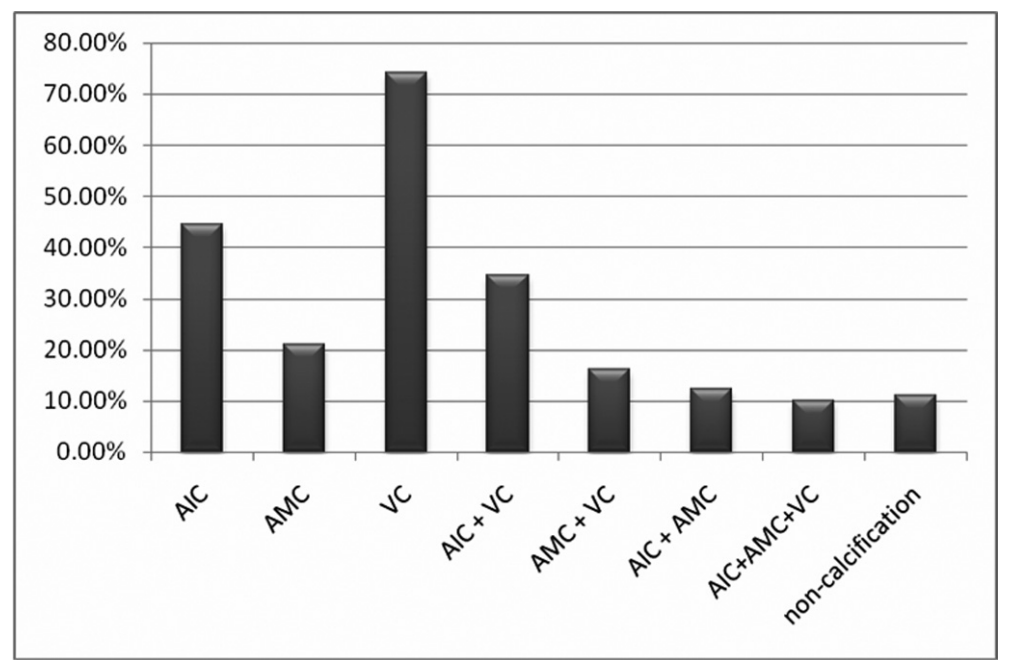

Fig. 1. The distribution of various type of cardiovascular calcification.

\subsection{Statistical analysis}

All statistical analyses were performed using the SPSS 15.0 software. Data are presented as means \pm S.D. ANOVA was used for comparison between non-calcification, AIC and AMC. Student's $t$-test was used for comparison in valvular calcification. Statistical comparison of baseline characteristics, underlying disease, and calcification type was performed by the chi-square test. Pearson's correlation analysis was used to examine the relationship between variables. To identify independent factors contributing to cardiovascular calcification, significant variables of univariate analysis were selected for logistic regression analysis. A value of $p<0.05$ was considered to be statistically significant.

\section{Results}

\subsection{Subject characteristics and distribution of cardiovascular calcification}

The mean age of the study population was $60.9 \pm$ 10.2 years, and male patients accounted for $49.4 \%$ of enrolled patients. Their mean hemodialysis duration was $75.8 \pm 47.1$ months. The distribution of the types of calcification is shown in Fig. 1. Fifty-three patients $(65.4 \%)$ had vascular calcification, including 36 (44.4\%) with AIC, and 17 (21\%) with AMC. Among them, 10 patients $(12.3 \%)$ had concurrent AIC and AMC. Echocardiography revealed 60 patients (74.1\%) had VC, including $44(54.3 \%)$ with aortic valve calci- fication, and 34 (42\%) with mitral valve calcification. Eighteen patients $(22 \%)$ showed calcification of both valves. Twenty-eight patients $(34.6 \%)$ had AIC with $\mathrm{VC}$ and $13(16 \%)$ had AMC with VC. Of the patients with VC, $46.5 \%$ and $21.6 \%$ of them demonstrated AIC and $\mathrm{AMC}$, respectively. It was estimated that $77.7 \%$ and $76.4 \%$ of AIC and AMC patients, respectively, had VC. Eight patients $(9.87 \%$ ) had AIC, AMC, and VC. Only 9 patients $(11.1 \%)$ did not have any evidence of calcification.

\subsection{Comparison between patients with calcification and non-calcification}

Table 1 displays the demographic and laboratory data of all patients. Compared with the non-calcification group, patients with AIC were older, had a higher prevalence of diabetes, and higher serum levels of IL6 and OPG (both $p<0.05$ ). Patients with AMC were older, had a higher prevalence of diabetes, and significantly higher levels of IL-6 and uric acid than those without calcification. The levels of serum calcium, phosphate, calcium phosphate products, total cholesterol, triglycerides, and parathyroid hormone were similar among the groups. There were significant differences in age and the prevalence of diabetes between the patients with AIC and AMC. Table 2 displays the results of the comparative data between patients with and without VC. Fetuin-A was found to be significantly lower in patients with VC. Although the dialysis duration was longer in these patients, this difference did not reach statistical significance. Both hs-CRP and IL-6 levels were similar between the 2 groups. 
Table 1

Clinical characteristic and biochemical data of hemodialysis patients with different type of vascular calcification

\begin{tabular}{|c|c|c|c|c|}
\hline & Total $(n=81)$ & $\mathrm{NC}(n=28)$ & $\operatorname{AMC}(n=17)$ & $\mathrm{AIC}(n=36)$ \\
\hline \multicolumn{5}{|l|}{ Demographic parameters } \\
\hline Age (years) & $60.9 \pm 10.2$ & $53.8 \pm 9.5$ & $60.3 \pm 5.9^{a}$ & $66.7 \pm 8.8^{\mathrm{b}, \mathrm{c}}$ \\
\hline Gender (male) & $40(49.4 \%)$ & $14(50 \%)$ & $7(41.2 \%)$ & $19(52.8 \%)$ \\
\hline Diabetes mellitus & $24(29.6 \%)$ & $2(7.1 \%)$ & $11(64.7 \%)^{\mathrm{b}}$ & $11(30.5 \%)^{\mathrm{a}, \mathrm{c}}$ \\
\hline Hypertension & $39(48.1 \%)$ & $13(46.4 \%)$ & $11(64.7 \%)$ & $15(41.6 \%)$ \\
\hline History of cardiovascular disease & $16(19.7 \%)$ & $5(17.9 \%)$ & $2(17.6 \%)$ & $9(22.2 \%)$ \\
\hline Duration on dialysis (months) & $75.8 \pm 47.1$ & $77.3 \pm 49.6$ & $70.3 \pm 49.8$ & $77.2 \pm 44.8$ \\
\hline \multicolumn{5}{|l|}{ Biochemical parameters } \\
\hline URR & $0.75 \pm 0.05$ & $0.76 \pm 0.05$ & $0.74 \pm 0.04$ & $0.74 \pm 0.05$ \\
\hline Blood hemoglobin (g/dL) & $10.2 \pm 0.9$ & $10.2 \pm 0.7$ & $10.2 \pm 0.8$ & $10.1 \pm 1.1$ \\
\hline Serum uric acid (mg/dL) & $6.8 \pm 1.2$ & $6.3 \pm 1.0$ & $7.3 \pm 1.2^{\mathrm{a}}$ & $6.9 \pm 1.2$ \\
\hline Serum albumin $(\mathrm{g} / \mathrm{dL})$ & $3.8 \pm 0.2$ & $3.8 \pm 0.3$ & $3.8 \pm 0.2$ & $3.8 \pm 0.2$ \\
\hline Serum calcium (mg/dL) & $9.2 \pm 0.6$ & $9.2 \pm 0.6$ & $9.3 \pm 0.6$ & $9.2 \pm 0.6$ \\
\hline Serum phosphate (mg/dL) & $4.9 \pm 1.0$ & $4.8 \pm 1.1$ & $5.1 \pm 0.9$ & $4.9 \pm 1.0$ \\
\hline Serum $\mathrm{Ca} \times \mathrm{PO}_{4}\left(\mathrm{mg}^{2} / \mathrm{dL}^{2}\right)$ & $46.3 \pm 11.0$ & $45.3 \pm 12.0$ & $48.6 \pm 10.4$ & $46.0 \pm 10.5$ \\
\hline Parathyroid hormone (pg/dL) & $436 \pm 680$ & $491 \pm 981$ & $390 \pm 523$ & $415 \pm 439$ \\
\hline Hs-CRP (mg/L) & $2.7 \pm 2.1$ & $2.5 \pm 2.1$ & $2.9 \pm 2.6$ & $2.7 \pm 1.9$ \\
\hline IL-6 (pg/mL) & $2.8 \pm 1.6$ & $1.9 \pm 0.9$ & $3.1 \pm 1.8^{\mathrm{a}}$ & $3.4 \pm 1.7^{\mathrm{b}}$ \\
\hline Fetuin-A $(\mu \mathrm{g} / \mathrm{mL})$ & $921 \pm 196$ & $957 \pm 195$ & $896 \pm 208$ & $906 \pm 193$ \\
\hline $\mathrm{OPG}(\mathrm{pmol} / \mathrm{L})$ & $10.9 \pm 3.7$ & $9.43 \pm 2.8$ & $11.9 \pm 4.8^{\mathrm{a}}$ & $11.8 \pm 3.6^{\mathrm{a}}$ \\
\hline $\mathrm{OPN}(\mathrm{ng} / \mathrm{mL})$ & $232.6 \pm 120.7$ & $243.6 \pm 138.9$ & $240.4 \pm 122.0$ & $219.4 \pm 105.8$ \\
\hline FGF23 (RU/mL) & $4287 \pm 4138$ & $4305 \pm 4183$ & $4164 \pm 4726$ & $4325 \pm 4002$ \\
\hline
\end{tabular}

NC vs. AMC or AIC: ${ }^{\mathrm{a}} p<0.05,{ }^{\mathrm{b}} p<0.001$. AMC vs. AIC: ${ }^{c} p<0.05$. URR: urea reduction rate; IL-6: interleukin-6; OPG: osteoprotegerin; OPN: osteopontin; FGF23: fibroblast growth factor 23.

Table 2

Clinical characteristic and biochemical data of hemodialysis patients with and without valvular calcification

\begin{tabular}{|c|c|c|c|}
\hline & $\operatorname{NVC}(n=21)$ & $\mathrm{VC}(n=60)$ & $P$ value \\
\hline \multicolumn{4}{|l|}{ Demographic parameters } \\
\hline Age (years) & $57.2 \pm 12.5$ & $62.2 \pm 9.1$ & 0.059 \\
\hline Gender (male) & $8(38.1 \%)$ & $32(53.3 \%)$ & 0.113 \\
\hline Diabetes mellitus & $8(38.1 \%)$ & $16(26.7 \%)$ & 0.324 \\
\hline Hypertension & $9(42.9 \%)$ & $30(50 \%)$ & 0.573 \\
\hline History of cardiovascular disease & $4(19 \%)$ & $12(20 \%)$ & 0.628 \\
\hline Duration on dialysis (months) & $60.8 \pm 44.0$ & $81.1 \pm 47.3$ & 0.089 \\
\hline \multicolumn{4}{|l|}{ Biochemical parameters } \\
\hline URR & $0.75 \pm 0.05$ & $0.75 \pm 0.05$ & 0.757 \\
\hline Blood hemoglobin (g/dL) & $10.2 \pm 1.1$ & $10.2 \pm 0.9$ & 0.770 \\
\hline Serum uric acid (mg/dL) & $6.9 \pm 1.2$ & $6.7 \pm 1.2$ & 0.641 \\
\hline Serum albumin $(\mathrm{g} / \mathrm{dL})$ & $3.8 \pm 0.3$ & $3.8 \pm 0.2$ & 0.514 \\
\hline Serum calcium $(\mathrm{mg} / \mathrm{dL})$ & $9.2 \pm 0.7$ & $9.2 \pm 0.5$ & 0.683 \\
\hline Serum phosphate $(\mathrm{mg} / \mathrm{dL})$ & $4.8 \pm 1.0$ & $4.9 \pm 1.0$ & 0.637 \\
\hline Serum $\mathrm{Ca} \times \mathrm{PO}_{4}\left(\mathrm{mg}^{2} / \mathrm{dL}^{2}\right)$ & $45.3 \pm 11.6$ & $46.6 \pm 10.8$ & 0.648 \\
\hline Parathyroid hormone (pg/dL) & $498 \pm 1156$ & $416 \pm 450$ & 0.650 \\
\hline Hs-CRP (mg/L) & $2.8 \pm 2.4$ & $2.6 \pm 2.0$ & 0.761 \\
\hline IL-6 (pg/mL) & $2.5 \pm 1.6$ & $3.0 \pm 1.7$ & 0.299 \\
\hline Fetuin-A $(\mu \mathrm{g} / \mathrm{mL})$ & $1009 \pm 172$ & $892 \pm 196$ & 0.024 \\
\hline $\mathrm{OPG}(\mathrm{pmol} / \mathrm{L})$ & $10.4 \pm 3.6$ & $11.1 \pm 3.8$ & 0.490 \\
\hline OPN (ng/mL) & $212.1 \pm 123.9$ & $239.6 \pm 120.0$ & 0.409 \\
\hline FGF23 (RU/mL) & $4718 \pm 4244$ & $4150 \pm 4140$ & 0.647 \\
\hline
\end{tabular}

URR: urea reduction rate; IL-6: interleukin-6; OPG: osteoprotegerin; OPN: osteopontin; FGF23: fibroblast growth factor 23.

Since diabetes is associated with a higher rate of vascular calcification, we further compared the clinical features and levels of the biochemical data and biomarkers in diabetic vs nondiabetic patients. Diabetic patients had a shorter dialysis duration (57.2 \pm
38.0 vs. $83.2 \pm 48.5$ months, $p=0.024)$, lower serum albumin $(3.7 \pm 0.3$ vs. $3.9 \pm 0.2 \mathrm{~g} / \mathrm{dL}, p=0.023)$, lower URR ( $0.72 \pm 0.04$ vs. $0.76 \pm 0.05, p=0.003)$, and $\mathrm{KT} / \mathrm{V}_{\text {urea }}(1.31 \pm 0.16$ vs. $1.47 \pm 0.21, p=$ $0.003)$, but had higher levels of OPG (12.6 \pm 3.8 vs. 
Table 3

Logistic regression analysis of three type of cardiovascular calcification

\begin{tabular}{|c|c|c|c|c|}
\hline Types of calcification & Independent variable & Odds ratio & C.I. $(95 \%)$ & $\mathrm{P}$ \\
\hline $\mathrm{AIC}$ & $\begin{array}{l}\text { Diabetes } \\
\text { Uric acid } \\
\text { Age }\end{array}$ & $\begin{array}{l}77.78 \\
5.324 \\
1.342\end{array}$ & $\begin{array}{c}1.577-3836 \\
1.753-16.169 \\
1.134-1.587\end{array}$ & $\begin{array}{l}0.029 \\
0.003 \\
0.001\end{array}$ \\
\hline AMC & $\begin{array}{l}\text { Diabetes } \\
\text { Uric acid } \\
\text { OPG }\end{array}$ & $\begin{array}{l}3043 \\
8.846 \\
1.728\end{array}$ & $\begin{array}{c}3.5-2574391 \\
1.073-72.945 \\
0.985-3.033\end{array}$ & $\begin{array}{l}0.02 \\
0.043 \\
0.056\end{array}$ \\
\hline $\mathrm{VC}$ & Fetuin-A & 0.997 & $0.994-1.000$ & 0.03 \\
\hline
\end{tabular}

Variables included for analysis of AIC: age, diabetes, uric acid, IL-6, OPG; Variables included for analysis of AMC: age, diabetes, uric acid, IL-6, OPG; Variables included for analysis of VC: age, HD duration, fetuin-A.

$10.3 \pm 3.6 \mathrm{pmol} / \mathrm{L}, p=0.024)$ and hs-CRP $(3.7 \pm 2.5$ vs. $2.3 \pm 1.9 \mathrm{mg} / \mathrm{L}, p=0.022$ ) as compared with nondiabetic subjects. However, there was no difference in age, uric acid, calcium, phosphate, IL-6, OPN, FGF23, and fetuin-A between the 2 groups.

\subsection{Correlation analysis}

The relationship between the variables tested was also examined. We found that FGF23 levels directly correlated with IL-6 $(r=0.447, p<0.001)$, calcium $(r=0.524, p<0.001)$, phosphate $(r=0.511$, $p<0.001)$, and the calcium phosphate product $(r=$ $0.605, p<0.001)$. However, no significant relationship between OPG and fetuin-A was noted. OPG levels were negatively correlated with calcium $(r=$ $-0.306, p=0.011)$, the calcium phosphate product $(r=-0.268, p=0.026)$, and albumin $(r=-0.381$, $p=0.001)$. Uric acid was strongly correlated with phosphate $(r=0.24, p=0.031)$ and the calcium phosphate product ( $r=0.231, p=0.038$ ). No significant association between uric acid and fetuin-A, IL-6, and hs-CRP was found. Serum IL-6 was shown to have a positive correlation with hs-CRP $(r=0.313, p=$ $0.013)$ and age $(r=0.358, p=0.002)$, and an inverse correlation with albumin $(r=-0.346, p=0.003)$. Fetuin-A did not have a significant relationship with serum calcium, phosphate, or other biomarkers.

\subsection{Logistic regression analysis of vascular and valvular calcification}

As shown in Table 3, multivariate regression analysis revealed age, diabetes, and uric acid levels were strongly related to AIC. Diabetes, uric acid, and OPG levels were independent factors associated with AMC. Fetuin-A was the sole independent associate of VC.

\section{Discussion}

Our results demonstrate that chronic hemodialysis patients have a high prevalence of cardiovascular calcification, with almost $90 \%$ of our subjects displaying image-documented calcification involving the arteries and or the cardiac valves. Furthermore, valvular calcification was more prevalent than peripheral artery involvement. Prevalence of AIC was twice that of AMC. Valvular involvement was observed in about $80 \%$ of the patients with arterial calcification. Besides traditional risk factors such as age and diabetes, uric acid and OPG were associated with vascular calcification, and fetuin-A with VC.

The prevalence of cardiovascular calcification varied greatly. Previous studies based on either computer tomography or echocardiography, have revealed a high prevalence of calcification, ranging from $28 \%$ to $77 \%$, of the aortic or the mitral valve in dialysis patients [14-16]. London et al. reported that $63.8 \%$ of their hemodialysis patients had arterial calcification, including $37.1 \%$ with AIC and $26.7 \%$ with AMC, as determined by radiography [10]. The variation of prevalence rate is greatly influenced by characteristics of study cohort such as age, dialysis duration, and prevalence of diabetes. Furthermore, different diagnostic tools examining various location of vascular calcification also present different results.

Several factors have been linked with cardiovascular calcification [17]. Among the traditional risk factors, our study confirmed both age and diabetes to be important determinants of vascular calcification. Diabetes is known as a risk factor for atherosclerosis. Since diabetes was associated with higher OPG level, this finding may explain at least partially why diabetes was at risk for vascular calcification. Our previous study has shown a strong association between chronic inflammation and disturbance of bone mineral metabolism in chronic hemodialysis patients [18]. The link between dysregulation of calcium, phosphate, and the 
parathyroid hormone, and cardiovascular calcification is controversial [3,19]. This discrepancy might be due to differences in study population, treatment modality, calcium load and phosphate binders. It is difficult to demonstrate the direct effect of calcium or phosphate on long-term events such as calcification because both calcium and phosphate levels usually changes frequently, and are rarely constant in hemodialysis patients.

In the general population, uric acid was identified as a risk factor for arterial calcification and also an independent determinant of coronary artery calcification [20]. In vitro studies have shown uric acid to induce proliferation and increase the expression of monocyte chemoattractant protein-1 in vascular smooth muscle cells [21]. Uric acid cal also causes endothelial dysfunction and chronic inflammation [22]. These findings suggest an active role of uric acid in mediating vascular lesions.

Among the calcification regulators evaluated in the present study, we found that diabetic patients had higher serum OPG levels, and that OPG was an independent predictor of AMC. OPG protects the skeleton from excessive bone resorption by binding to the receptor activator of the NF-kappaB ligand, which upregulates inflammation mediators and vascular calcification [23]. High levels of serum OPG were associated with rapid progressive vascular calcification, and OPG was also found to be an independent determinant of coronary artery calcification and mortality in patients with chronic kidney disease [24]. It should be noted that despite its biological ability of anticalcification, elevation of serum OPG was associated with advanced vascular calcification. An incomplete compensatory response is considered to explain this discrepancy [25].

Fetuin-A was shown to be a predictor of mortality in dialysis patients [26]. However, the relationship between fetuin-A and cardiovascular calcification remains unclear [19]. Recent studies reported that inflammation was an important modulatory factor of fetuin-A $[27,28]$. We found low fetuin-A levels to be the only risk factor of $\mathrm{VC}$ in our study subjects. Although patients with $\mathrm{VC}$ tended to be older and with a longer duration of dialysis, there were no significant differences in other markers of inflammation.

Serum phosphate and calcium have been demonstrated to be associated with FGF23 levels in hemodialysis patients [29]. More recently, FGF23 has been found to be correlated with outcome in chronic hemodialysis patients [30]. FGF23 inhibits phosphate reab- sorption and reduces the renal synthesis of $1,25(\mathrm{OH})_{2} \mathrm{D}$. Nonetheless, the role of FGF23 in cardiovascular calcification is uncertain. Although FGF23 levels correlated with pro-inflammatory cytokines, calcium, phosphate, and their products, calcification was not associated with significant changes in FGF23 in our study. Plasma FGF23 level has been shown to be an independent factor in peripheral vascular calcification of male hemodialysis patients [31]. One recent study demonstrated that FGF23 was associated with severe but not moderate coronary artery calcification in non-dialysis chronic kidney disease patients [32]. Apparently, more evidence is required to establish the role of FGF23 in vascular calcification.

Our study has several limitations. First, diagnosis of vascular calcification in the present study depends on objective interpretation. Quality of radiogram may influence the interpretation. Second, treatment effect on cardiovascular calcification was not assessed in the present study. A longitudinal follow up study with various regimens to address hyperphosphatemia and hyperparathyroidism may provide more information regarding their impact on calcification in different locations. Lastly, due to its cross-sectional design, the association between biomarkers and cardiovascular calcification in the present study does not suggest the casual relationship. Further study is required to establish the direct role of biomarkers.

In conclusion, cardiovascular calcification was very prevalent in chronic hemodialysis patients and cardiac valve was more frequently involved than peripheral artery. In addition to diabetes, uric acid was associated with vascular calcification. Level of circulating OPG was linked with medial calcification, and fetuin-A significantly correlated with calcification of the cardiac valves. Identification of these biomarkers is helpful for the assessment of vascular calcification.

\section{References}

[1] Tsai YC, Lee CT, Huang TL, Cheng BC, Kuo CC, Su Y, Ng HY, Yang CC, Chuang FR, Liao SC. Inflammatory marker but not adipokine predicts mortality among long-term hemodialysis patients. Mediators Inflamm 2007; 2007: 19891-19895.

[2] Blacher J, Guerin AP, Pannier B, Marchais SJ, London GM. Arterial calcifications, arterial stiffness and cardiovascular risk in end-stage renal disease. Hypertension 2001; 38: 938942.

[3] Wang AY, Wang M, Woo J, Lam CW, Li PK, Lui SF, Sanderson JE. Cardiac valve calcification as an important predictor for all-cause mortality and cardiovascular mortality in longterm peritoneal dialysis patients: A prospective study. J Am Soc Nephrol 2003; 14: 159-168. 
[4] Kuzela DC, Huffer WE, Conger JD, Winter SD, Hammond WS. Soft tissue calcification in chronic dialysis patients. Am J Pathol 1977; 86: 403-424.

[5] Block GA, Spiegel DM, Ehrlich J, Mehta R, Lindbergh J, Dreisbach A, Raggi P. Effects of sevelamer and calcium n coronary artery calcification in patients new to hemodialysis. Kidney Int 2005; 68: 1815-1824.

[6] Dellegrottaglie S, Sanz J, Rajagopalan S. Molecular determinants of vascular calcification: A bench to bedside view. Curr Mol Med 2006; 6: 515-524.

[7] Shanahan CM, Cary NR, Salisbury JR, Proudfoot D, Weissberg PL, Edmonds ME. Medial localization of mineralizationregulating proteins in association with Mönckeberg's sclerosis: Evidence for smooth muscle cell-mediated vascular calcification. Circulation 1999; 100: 2168-2176.

[8] Vattikuti R, Towler DA. Osteogenic regulation of vascular calcification: An early perspective. Am J Physiol Endocrine Metab 2004; 286: E686-696.

[9] Wang AY, Ho SS, Wang M, Liu EK, Ho S, Li PK, Lui SF, Sanderson JE. Cardiac valvular calcification as a marker of atherosclerosis and arterial calcification in end-stage renal disease. Arch Intern Med 2005; 165: 327-332.

[10] London GM, Guérin AP, Marchais SJ, Métivier F, Pannier $\mathrm{B}$, Adda $\mathrm{H}$. Arterial media calcification in end-stage renal disease: impact on all-cause and cardiovascular mortality. Nephrol Dial Transplant 2003; 18: 1731-1740.

[11] Mizobuchi M, Towler D, Slatopolsky E. Vascular calcification: The killer of patients with chronic kidney disease. J Am Soc Nephrol 2009; 20: 1453-1464.

[12] Lee CT, Tsai YC, Su CY, Ng HY, Hsu CY, Ko SF, Chen TC, Kuo CC, Yang CC, Chiou TY, Lee WC, Yang YK, Lam KK. Interleukin 10 and residual kidney function are associated with risk of vascular calcification in patients undergoing peritoneal dialysis. Clinical Nephrology 2011; 75: 397-402.

[13] Gotch FA, Sargent JA. A mechanistic analysis of the National Cooperative Dialysis Study (NCDS). Kidney Int 1985; 28 : 526-534.

[14] Ribeiro S, Ramos A, Brandão A, Rebelo JR, Guerra A, Resina C, Vila-Lobos A, Carvalho F, Remédio F, Ribeiro F. Cardiac valve calcification in haemodialysis patients: role of calciumphosphate metabolism. Nephrol Dial Transplant 1998; 13: 2037-2040.

[15] Maher ER, Young G, Smyth-Walsh B, Pugh S, Curtis JR. Aortic and mitral valve calcification in patients with end-stage renal disease. Lancet 1987; 2: 875-877.

[16] Ikee R, Honda K, Oka M, Maesato K, Mano T, Moriya H, Ohtake T, Kobayashi S. Association of heart valve calcification with malnutrition-inflammation complex syndrome, betamicroglobulin, and carotid intima media thickness in patients on hemodialysis. Ther Apher Dial 2008; 12: 464-468.

[17] Cozzolino M, Mazzaferro S, Pugliese F, Brancaccio D. Vascular calcification and uremia: what do we know? Am J Nephrol 2008; $28: 339-346$

[18] Lee CT, Tsai YC, Ng HY, Su Y, Lee WC, Lee LC, Chiou TT, Liao SC, Hsu KT. Association between C-reactive protein and biomarkers of bone and mineral metabolism in chronic hemodialysis patients: A cross-sectional study. J Ren Nutr 2009; 19: 220-227.

[19] Wang AY, Lam CW, Wang M, Chan IH, Yu CM, Lui SF, Sanderson JE. Increased circulating inflammatory proteins predict a worse prognosis with valvular calcification in endstage renal disease: A prospective cohort study. Am J Nephrol 2008; $28:$ 647-653.

[20] Kasifoglue T, Cansu D, Korkmaz C. Widespread arterial calcification in a patient with gout. Intern Med. 2008; 47: 481.

[21] Kanellis J, Watanabe S, Li JH, Kang DH, Li P, Nakagawa T, Wamsley A, Sheikh-Hamad D, Lan HY, Feng L, Johnson RJ. Uric acid stimulates monocyte chemoattractant protein1 production in vascular smooth muscle cells via mitogenactivated protein kinase and cyclooxygenase-2. Hypertension 2003; 41: 1287-1293.

[22] Kanellis J, Kang DH. Uric acid as a mediator of endothelial dysfunction, inflammation, and vascular disease. Semin Nephrol 2005; 25: 39-42.

[23] Collin-Osdoby P. Regulation of vascular calcification by osteoclast regulatory factors RANKL and osteoprotegerin. Circ Res 2004; 95: 1046-1057.

[24] Mesquita M, Demulder A, Damry N, Méot C, Wittersheim E, Willems D, Dratwa M, Bergmann P. Plasma osteoprotegerin is an independent risk factor for mortality and an early biomarker of coronary vascular calcification in chronic kidney disease. Clin Chem Lab Med 2009; 47: 339-346.

[25] Demer LL, Tintut Y. Vascular calcification: Pathobiology of a multifaceted disease. Circulation 2008; 117: 2938-2948.

[26] Honda H, Qureshi AR, Heimbürger O, Barany P, Wang K, Pecoits-Filho R, Stenvinkel P, Lindholm B. Serum albumin, C-reactive protein, interleukin 6 , and fetuin a as predictors of malnutrition, cardiovascular disease, and mortality in patients with ESRD. Am J Kidney Dis 2006; 47: 139-148.

[27] Metry G, Stenvinkel P, Qureshi AR, Carrero JJ, Yilmaz MI, Bárány P, Snaedal S, Heimbürger O, Lindholm B, Suliman ME. Low serum fetuin-A concentration predicts poor outcome only in the presence of inflammation in prevalent haemodialysis patients. Eur J Clin Invest 2008; 38: 804-811.

[28] Hermans MM, Brandenburg V, Ketteler M, Kooman JP, van der Sande FM, Gladziwa U, Rensma PL, Bartelet K, Konings CK, Hoeks AP, Floege J, Leunissen KM. Study on the relationship of serum fetuin-A concentration with aortic stiffness in patients on dialysis. Nephrol Dial Transplant 2006; 21: 1293-1299.

[29] Imanishi Y, Inaba M, Nakatsuka K, Nagasue K, Okuno S, Yoshihara A, Miura M, Miyauchi A, Kobayashi K, Miki T, Shoji T, Ishimura E, Nishizawa Y. FGF-23 in patients with end-stage renal disease on hemodialysis. Kidney Int 2004; 65: 1943-1946.

[30] Gutiérrez OM, Mannstadt M, Isakova T, Rauh-Hain JA, Tamez H, Shah A, Smith K, Lee H, Thadhani R, Jüppner H, Wolf M. Fibroblast growth factor 23 and mortality among patients undergoing hemodialysis. N Engl J Med 2008; 359: 584-592.

[31] Inaba M, Okuno S, Imanishi Y, Yamada S, Shioi A, Yamakawa T, Ishimura E, Nishizawa Y. Role of fibroblast growth factor-23 in peripheral vascular calcification in nondiabetic and diabetic hemodialysis patients. Osteoporos Int 2006; 17: 1506-1513.

[32] Morena M, Jaussent I, Halkovich A, Dupuy AM, Bargnoux AS, Chenine L, Leray-Moragues H, Klouche K, Vernhet H, Canaud B, Cristol JP. Bone biomarkers help grading severity of coronary calcification in non dialysis chronic kidney disease patients. PLoS One 2012; 7: e36175. 


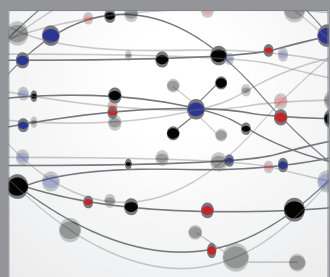

The Scientific World Journal
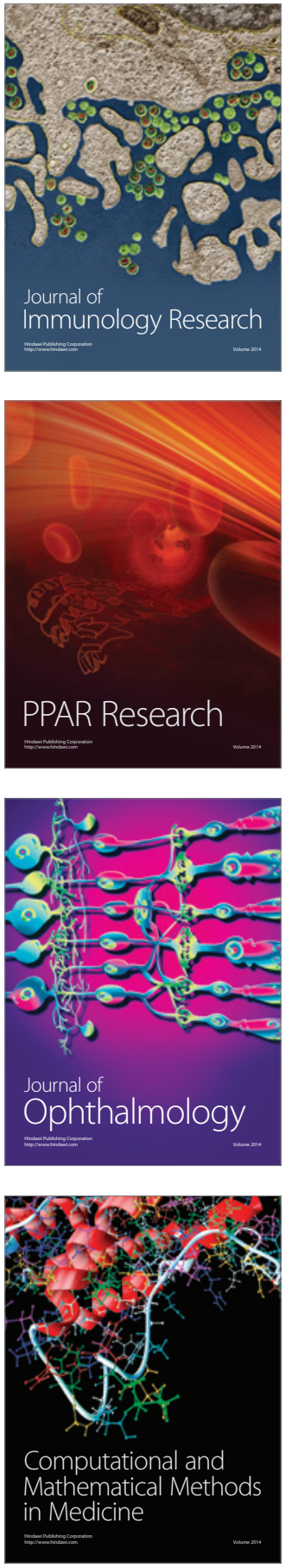

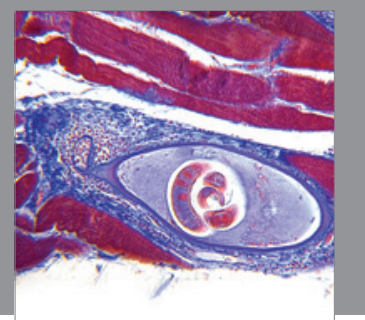

Gastroenterology

Research and Practice
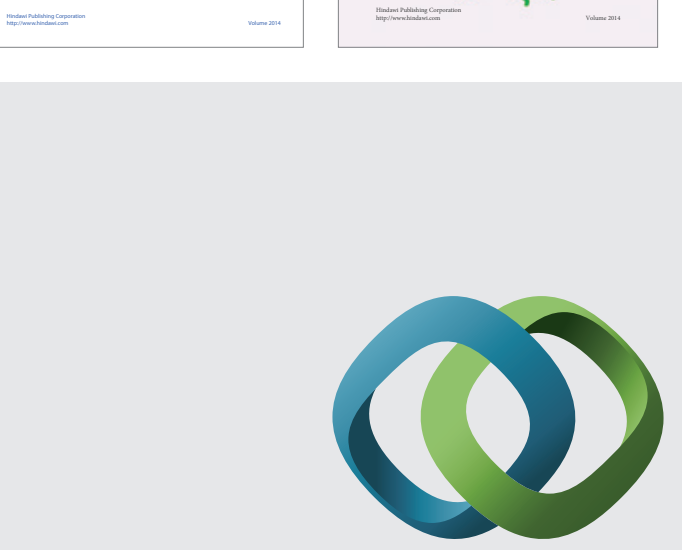

\section{Hindawi}

Submit your manuscripts at

http://www.hindawi.com
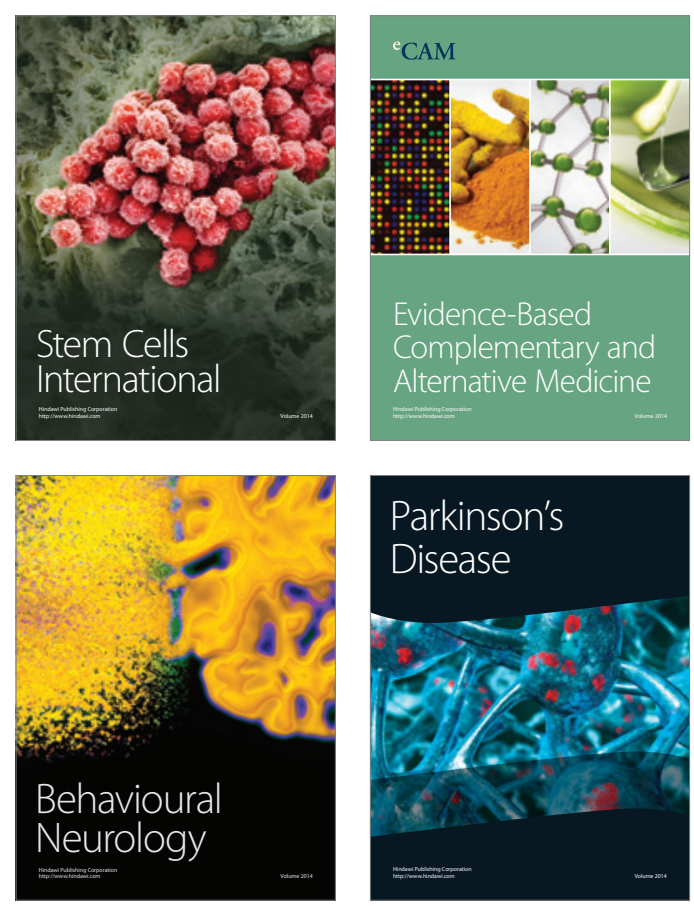

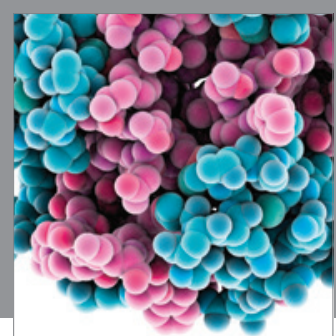

Journal of
Diabetes Research

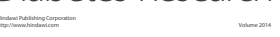

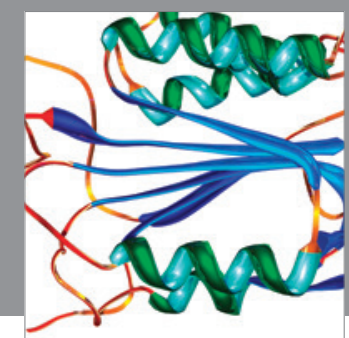

Disease Markers
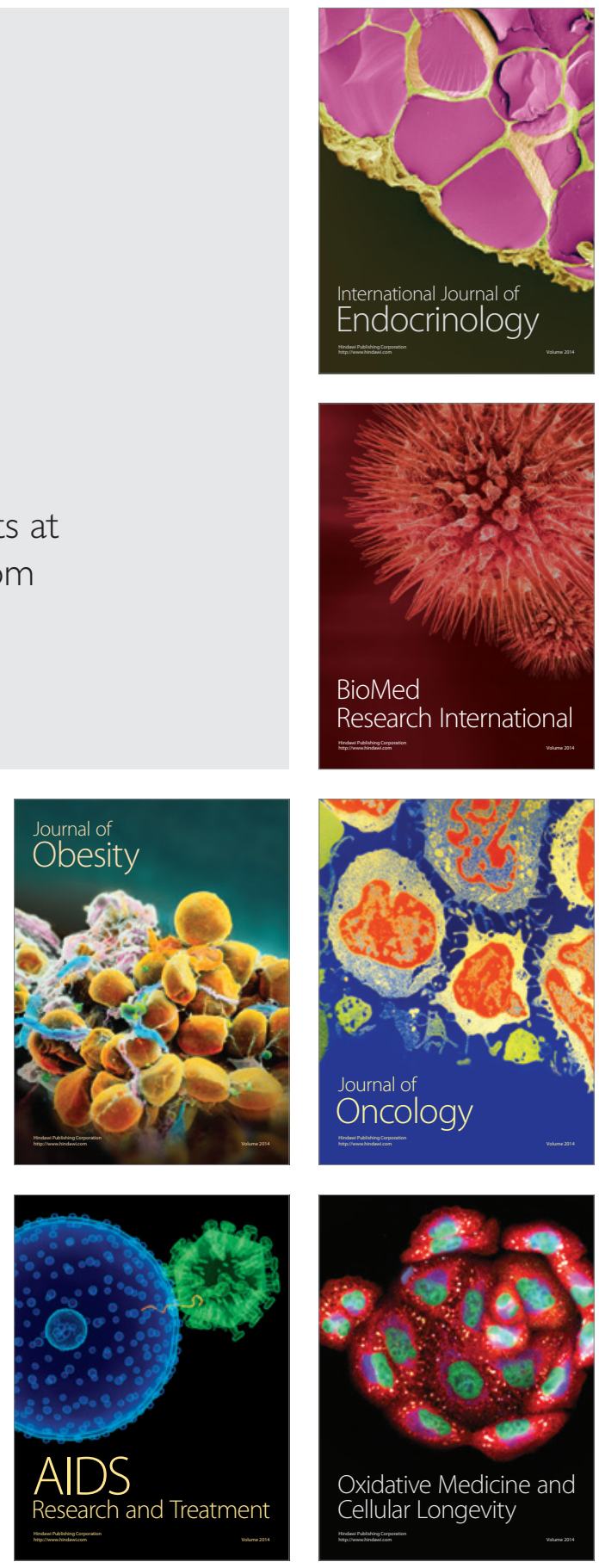